\title{
TRIBUTACIÓN Y DESARROLLO EN PERSPECTIVA
}

Isidro Hernández Rodríguez*

$\mathrm{D}$ esarrollo" y "subdesarrollo" forman una pareja de conceptos dicotómicos. El término dominante es "desarrollo" y su contrario, "subdesarrollo", se define en forma negativa o por oposición a "desarrollo" 1 . Un país se considera desarrollado cuando las relaciones sociales dominantes están regidas por la lógica de la economía de mercado, la estructura productiva se basa en los sectores secundario y terciario superior ${ }^{2}$ y tiene un Estado unificado que opera en un sistema político de democracia liberal. Ahora bien, al comparar a cualquier país con estos criterios siempre hay una brecha en alguno de esos aspectos, por ejemplo, puede tener unas relaciones sociales totalmente permeadas por el mercado pero una estructura productiva de tipo

* Magíster en Teoría y Política Económica y candidato a Doctor en Economía de la Universidad de Barcelona, profesor de la Universidad Externado de Colombia, Bogotá, Colombia [isidro.hernandez@uexternado.edu.co]. Agradezco a Luis I. Aguilar, Bill Céspedes, Carolina Esguerra, Jorge I. González, Lucía Montoya, Ana M. Oliveros, Adriana Edu P., Mauricio Pérez S., Édgar Revéiz, Giancarlo Romano G., Alberto Supelano, Hugo Torres A. y Jorge Vivas R., quienes con su lectura juiciosa me hicieron ver las incoherencias y vacíos de una versión anterior. Fecha de recepción: 8 de noviembre de 2010, fecha de modificación: 25 de febrero de 2011, fecha de aceptación: 6 de mayo de 2011.

${ }^{1}$ Para Bauer (1971), el término subdesarrollo es omnicomprensivo y definirlo en forma negativa es engañoso pues "No especifica las similitudes y oscurece las diferencias. Por tanto, no puede indicar las limitaciones de las semejanzas ni la amplitud y profundidad de las diferencias. Crea la tentación de encontrar uniformidades donde no existen" (p. 7). En su concepción del desarrollo como crecimiento económico, los conceptos subdesarrollo y en vías de desarrollo "son eufemismos inapropiados: subdesarrollo porque sugiere que la situación que describe es anormal, reprensible y quizá fácilmente rectificable; en vías de desarrollo porque lleva a contradicciones tales como las referencias al estancamiento o retroceso del mundo en desarrollo" (p. 15).

${ }^{2}$ El sector terciario superior comprende los servicios de desarrollo tecnológico y científico y de actividades profesionales como la medicina y la ingeniería que generan alto valor agregado. 
primario o un sistema político dictatorial. Así, en la práctica existe una gran heterogeneidad y, justamente por ello, el subdesarrollo es necesariamente una cuestión de grado frente a esos parámetros ideales. En síntesis, el concepto de subdesarrollo indica una transformación continua de las estructuras económicas, políticas y sociales hacia una sociedad de mercado y democracia liberal.

En política internacional, desde 1945 hasta los años setenta, el interés de los gobiernos por el subdesarrollo estuvo motivado por la discusión sobre el progreso social, económico y cultural y el respeto a los derechos humanos. La mayoría de las misiones internacionales de esa época se organizaron, financiaron y ejecutaron con esos propósitos. En el ambiente de la segunda postguerra, dentro de las acciones estratégicas que se llevaron a cabo para alcanzar el anhelado desarrollo, la tributación era un componente básico que permitiría, junto con la ayuda internacional, aumentar los recursos fiscales y financiar el progreso de los países subdesarrollados.

Los investigadores nacionales y las misiones internacionales sobre la tributación en los países subdesarrollados concluyeron que la elasticidad del impuesto respecto del ingreso nacional no concordaba con los efectos previstos por la teoría. Las investigaciones empíricas que se hicieron desde los años setenta hasta ahora confirman ese resultado inicial. E1 corolario obtenido es que la teoría macroeconómica pierde generalidad cuando se consideran diversos tipos de economías y que, la mayoría de las veces, las autoridades económicas van a ciegas en el diseño de sus estructuras tributarias ${ }^{3}$.

En los centros académicos existía y aún existe un acuerdo sobre las dificultades de los modelos teóricos dominantes para explicar la dinámica del mundo subdesarrollado. Todos saben que tienen características económicas que los hacen diferentes, entre ellas el predominio de mercados segmentados y en desequilibrio permanente; la gran volatilidad macroeconómica; la falta de capacidad política y económica para aislar los choques externos derivados, por ejemplo, de los términos de intercambio o las tasas de interés internacionales; el peso excesivo del servicio de la deuda externa en el presupuesto y la balanza de pagos; la gran inestabilidad de la tasa de cambio; la represión financiera y, en materia tributaria, la gran participación de los impuestos al comercio exterior en el recaudo total y unos niveles de gravámenes directos inferiores a los de los países desarrollados. Estas diferencias obligarían en sí mismas a elaborar un enfoque teórico que

${ }^{3}$ La distribución de cada tipo de impuesto en la carga fiscal total.

Revista de Economía Institucional, vol. i3, n.o 24 , Primer semestre/20it, pp. 27 i-302 
capte sus particularidades y, por tanto, a tomar con cautela las teorías dominantes en los países desarrollados.

Los investigadores que estudian las discrepancias entre la teoría y los hechos tributarios en el subdesarrollo proponen explicaciones alternativas. Unos enfatizan las estructuras económicas, otros ponen de relieve lo institucional, algunos combinan las dos anteriores y hay quienes piensan que basta hacer ligeros ajustes desde la teoría microeconómica para cerrar la brecha entre las predicciones del modelo dominante y los resultados de los estudios empíricos.

Este ensayo hace una revisión panorámica del debate sobre la imposición en el subdesarrollo para resaltar los puntos en discusión y las propuestas de política que se han sugerido; mostrar las relaciones entre hechos económicos y evolución de las concepciones teóricas, de la política económica en general y de la política tributaria en particular, y destacar un elemento olvidado por las interpretaciones sobre la tributación en los países subdesarrollados: las diferencias en las preferencias de la sociedad política por la tributación.

La primera sección muestra cómo se planteó inicialmente el debate sobre la relación entre desarrollo y tributación. La segunda sección muestra cómo cambió la discusión desde la década de los setenta, debido a los cambios en el desarrollo mundial y en la manera de abordar los temas económicos en el mundo académico. En la tercera se argumenta que entre los factores que explican la baja presión tributaria y la inelasticidad ingreso del recaudo en el subdesarrollo se debe incluir la preferencia de los Estados por la tributación, puesto que las acciones que dieron origen y configuraron a las sociedades políticas del mundo subdesarrollado determinan esa preferencia. En la última sección se presentan las conclusiones.

\section{EL INICIO DEL DEBATE}

La teoría del desarrollo económico estaba en auge a mediados del siglo pasado. La discusión era amplia, desde el concepto mismo de desarrollo hasta sus determinantes. Unos argumentaban que el desarrollo era un proceso acumulativo de cambio de la estructura económica, otros lo concebían como evolución o como progreso, algunos lo asimilaban a crecimiento económico ${ }^{4}$ y unos más lo equiparaban a industrializa-

\footnotetext{
${ }^{4}$ En el debate sobre el desarrollo social es frecuente confundir desarrollo con crecimiento económico. Algunos investigadores usan ambos términos como sinónimos, un uso equivocado pues el desarrollo implica transformaciones radicales en las estructuras sociales vigentes, compuestas por lo económico, lo político y las demás relaciones sociales. Si se habla de desarrollo económico habría en-
} 
ción ${ }^{5}$. En el debate se hacía énfasis en aspectos como la demografía, el financiamiento, el mercado laboral, los términos de intercambio, la industrialización, la planeación económica, el gasto público y los impuestos, la dependencia político-económica y el imperialismo ${ }^{6}$.

Quienes participaban en la controversia resaltaron las diferencias entre países desarrollados y subdesarrollados. En particular, que en los primeros la formación de capital estaba garantizada por flujos suficientes de ingreso y ahorro privado, mientras que en los segundos esos flujos eran exiguos y constituían una restricción fuerte para acelerar el crecimiento y el desarrollo. En el ámbito fiscal se destacó que las autoridades económicas de los países desarrollados podían fijar un nivel de gasto público compatible con la meta de crecimiento, pues el efecto multiplicador del gasto y la fuerte dinámica de la actividad privada volvían endógeno el nivel de recaudo que financia el gasto ${ }^{7}$, mientras que en los subdesarrollados el gasto del gobierno está limitado por la baja capacidad impositiva.

La experiencia internacional mostraba que para superar la restricción fiscal, en el subdesarrollo los gobiernos escogían entre diferentes fuentes para sufragar sus gastos: deuda interna y externa, emisión primaria de dinero y monopolio de recursos, especialmente las rentas mineras y de hidrocarburos. Los investigadores encontraron que la estrategia más utilizada por las autoridades económicas era una combinación de emisión y deuda externa, que aceleraba la inflación y llevaba a una fuga de valor agregado en un monto equivalente al del pago de intereses de la deuda externa.

La pregunta era qué y cómo hacer para superar la restricción de financiamiento del crecimiento y lograr un avance acelerado del capitalismo. Para superar la barrera fiscal y las restricciones estructurales, entre 1950 y 1970 se propuso que el eje central de la política debería ser la tributación. Las misiones internacionales encontraban que debían identificar las barreras económicas e institucionales para diseñar tonces que considerar el cambio de la estructura económica básica y no sólo el crecimiento.

${ }^{5}$ Sunkel y Paz (1982) sintetizan la problemática y los enfoques desde la perspectiva latinoamericana.

${ }^{6}$ La bibliografía es prolífica; aquí se destacan autores clásicos como Rostow (1960), Kuznets (1966), CEPAL (1949), Chenery (1960), Chenery y Syrquin (1975), Furtado (1965), Kalecki (1976), McKinnon (1974), Singer (1952), Prebisch (1949), Nurkse (1953), W. A. Lewis (1955 y 1966), S. R. Lewis (1963), Heller y Kauffman (1965), Bird y Oldman (1967) y Hinrichs (1967).

${ }^{7}$ Los multiplicadores simples del gasto público y la tributación muestran que el efecto expansivo del gasto del gobierno en el ingreso real es mayor que el efecto negativo de la imposición. De acuerdo con el teorema del presupuesto equilibrado, el gobierno debe recaudar en cada periodo los ingresos suficientes para financiar su plan de gasto y evitar la deuda pública. 
nuevas estructuras tributarias. Una de las preguntas fundamentales que guiaron sus esfuerzos interpretativos era la de por qué es tan baja la tributación en los países subdesarrollados.

Los estudios detectaban una anomalía en el comportamiento del nivel impositivo. Mientras que según las teorías neoclásica y keynesiana el recaudo es función creciente del nivel de ingreso y relativamente elástico, los resultados estadísticos indicaban que si bien se mantenía la relación positiva entre ingreso nacional y recaudo, el recaudo es inelástico con respecto al ingreso nacional (cuadro 1 ).

La evidencia disponible hasta mediados de siglo llevó a que Hinrichs (1967) propusiera que en el diseño de estrategias de política tributaria en los países subdesarrollados se abandonara la relación positiva que postula la teoría y se adoptara una teoría del cambio de estructura impositiva a partir de las etapas de desarrollo8.

Su idea concordaba con los planteamientos de Clark (1939) y Rostow (1960) sobre el desarrollo económico, en boga en esa época. Para estos autores y sus seguidores el subdesarrollo era una etapa de un proceso: los choques exógenos modificaban las estructuras económicas y de comportamiento y los países subdesarrollados entraban primero en una senda de despegue $-\mathrm{O}$ aumento del coeficiente de inversión y establecimiento de al menos una rama industrial-, luego maduraba el sistema de mercado - modernización del aparato productivo y dominio social de los empresarios-, y al final se llegaba al consumo masivo. Esa secuencia significaba que desarrollarse equivalía a capitalismo de producción y consumo masivo. De ahí se infería que en cada etapa se debía diseñar e implantar una estructura tributaria acorde con el tipo de actividad predominante; cuando se llegara al estadio superior la imposición tendría la misma estructura que en los países más desarrollados.

El examen de la propuesta analítica de Hinrichs concluyó que no explicaba las fuentes de cambio de la secuencia y se limitaba a justificar la estructura por la estructura misma o por algunas características que, a priori, se consideraban las más importantes en cada fase. En la parte empírica, los análisis comparativos encontraron divergencias significativas entre países subdesarrollados puesto que, como el mismo Hinrichs sugería, sus estructuras impositivas eran un tapiz multicolor

\footnotetext{
${ }^{8}$ En la sociedad tradicional, donde el sector agropecuario aporta la mayor parte del valor agregado y las transacciones no son monetizadas, predominarían los impuestos tradicionales: diezmos, gravámenes a la tierra y los servicios personales y participaciones en el producto agropecuario. En la segunda etapa, sociedad de transición, dominarían los impuestos al comercio exterior que darían paso a tributos indirectos internos. En la última, sociedad moderna, se repartirían entre impuestos directos e indirectos internos a personas y empresas, casi proporcionalmente.
} 


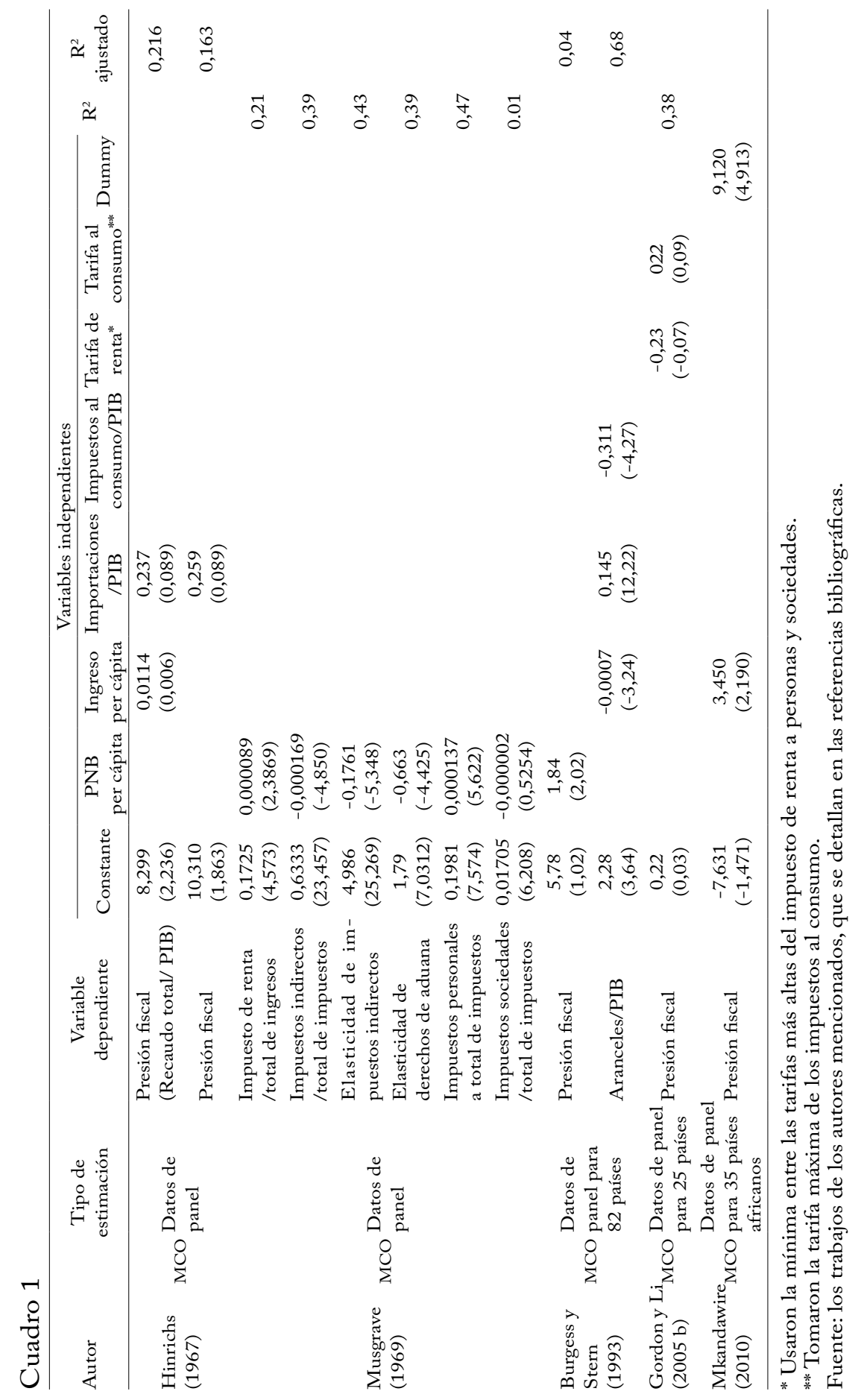

Revista de Economía Institucional, vol. i3, N.o 24 , Primer Semestre/20it, Pp. 27I-302 
que limitaba la generalización. Ahmad y Stern (1989) mostraron que la hipótesis del patrón de cambio de Hinrichs es difícil de sustentar incluso en un mismo país cuando se hace un análisis econométrico de series de tiempo.

Había que explicar el fenómeno y se plantearon diversas hipótesis. Algunos argumentaron que entre las causas de la inelasticidad ingreso del recaudo y la exigua tributación se encontraban la actitud rentista de los dueños de la riqueza ${ }^{9}$, los niveles de pobreza y la incompetencia de la administración tributaria para elevar el recaudo, que se traducían en un ahorro público nulo y en una trampa fiscal que restringía el apoyo fiscal al desarrollo.

Heller (1954) propuso una interpretación basada en el origen de las estructuras tributarias existentes que partía de la observación del tipo de sistema tributario ${ }^{10}$ vigente en algunos países subdesarrollados: la instrumentalización tributaria en América Latina estaba condicionada por la herencia española del sistema impositivo in rem $^{11}$. Musgrave (1969) complementó esa sugerencia y sostuvo que un país subdesarrollado puede implantar un sistema personal sólo cuando alcanza una organización económica de mayor jerarquía que se manifiesta en tres aspectos básicos: amplio uso del dinero como medio para realizar las transacciones de bienes y servicios, presencia de establecimientos grandes que tienen mayor permanencia en la economía y concentrarán la mayoría de empleo, y una estructura económica con dominio del sector industrial sobre el agropecuario.

Otros investigadores plantearon que las características económicas e institucionales del subdesarrollo explican su dinámica tributaria (Lotz y Morss, 1967). Entre las características económicas se destacan la vulnerabilidad a fluctuaciones externas, pues tienen un alto grado de apertura y dependen de la exportación de bienes primarios para generar divisas e importar bienes de capital y garantizar el crecimiento económico, la alta participación del sector primario en el producto,

${ }^{9}$ Que se apropian parte del ingreso nacional a través de pagos que reciben por sus derechos de propiedad del suelo, intereses de la deuda pública, valorización de joyas, etc. En el sentido clásico la renta es el ingreso "no ganado", derivado de la propiedad, diferente del ingreso ganado que proviene del trabajo (sueldos y salarios) y la inversión riesgosa en actividades productivas (ganancias del capital).

${ }_{10}$ Articulación de un conjunto de impuestos que reparten la carga fiscal entre los contribuyentes y guardan reciprocidad con los propósitos del gasto público.

${ }^{11}$ Los sistemas tributarios se clasifican en históricos y racionales. El sistema in rem, objetivo o real, es parte de los sistemas históricos y se caracteriza porque la base imponible es un objeto, es decir, el impuesto se basa en características objetivas de las cosas materiales o inmateriales (Einaudi, 1958, y Fuentes, 1990). En general este tipo de impuestos son de tipo celular, no son progresivos y la base imponible es indiciaria, es decir, se usan características físicas del objeto: medidas de volumen o de longitud, localización, etc. 
el excesivo peso de la población rural, la alta proporción de autoempleo, la dualidad entre economía atrasada y economía moderna, y la profunda desigualdad en la distribución del ingreso.

Musgrave (1969) puso énfasis particular en las características institucionales y como condicionantes de la elasticidad del recaudo impositivo identificó el analfabetismo, la aceptación social del alto grado de incumplimiento de las obligaciones tributarias, la ausencia de contabilidad en el sector privado y la poca capacidad de gestión de la administración tributaria.

Desde finales de los años sesenta aumentó el acervo de información sobre las economías subdesarrolladas. Las investigaciones encontraron diferencias significativas en los tres componentes de las finanzas públicas. En materia de gasto público mostraron que su asignación se concentra en administración general, defensa, educación y servicio de la deuda externa (Burgess y Stern, 1993). En tributación destacaron el predominio de los impuestos indirectos, al comercio exterior y a las ventas internas, sobre los impuestos directos, y que en estos últimos las empresas pagaban más que las personas naturales o físicas por impuesto de renta. En cuanto al financiamiento encontraron que las autoridades fiscales cubrían el déficit con una combinación de deuda externa, señoreaje, impuesto de inflación y rentas de monopolios mineros y de hidrocarburos.

Conforme a los diagnósticos se sugirió una política tributaria que fijara impuestos elevados y selectivos para cambiar la dirección de los recursos que se usaban en actividades poco rentables y especulativas ${ }^{12}$ hacia actividades productivas, y del consumo de bienes de lujo hacia el ahorro (Bird y Oldman, 1967). También se propuso reforzar la tributación de la renta y hacerla más progresiva, con altas tarifas para los más acaudalados (Kaldor, 1967). Se esperaba que esta estrategia indujera mayor formación de capital privado y apalancara recursos para gasto público en educación, salud e infraestructura.

En suma, mientras que en los países desarrollados el gasto público determinaba el nivel de ingresos tributarios, en los países subdesarrollados el nivel de recaudo establecía las posibilidades de gasto público e inducía financiamientos inflacionarios del crecimiento. Mientras que en los primeros el volumen de recaudo se relacionaba con el nivel de ingreso, en los segundos el coeficiente era nulo. Las explicaciones de esta anomalía son diversas pero cabe destacar que la presión tributaria en los países subdesarrollados es mínima por el

\footnotetext{
${ }^{12}$ Como las inversiones en bienes raíces, metales preciosos o moneda extranjera.
}

Revista de Economía Institucional, vol. i3, n.o 24 , Primer semestre/20it, pp. 27 i-302 
escaso desarrollo industrial, la fuerte presencia de un sector informal o de difícil tributación, la desigualdad en la distribución del ingreso y el origen del sistema tributario.

\section{LA CAUSALIDAD SE INVIERTE}

Como fruto de las circunstancias, a finales de los años setenta la visión de la tributación en los países subdesarrollados empezó a cambiar -igual que la de otros temas de teoría económica- en un proceso que duró algo más de una década y en el que participaron activamente misiones internacionales, organismos multilaterales ${ }^{13}$, autoridades económicas locales y nacientes centros de pensamiento.

En esos años, los países desarrollados mostraron resultados macroeconómicos que, en plena Guerra Fría, se consideraban desventajosos comparados con los de los países socialistas -aceleración de la inflación ${ }^{14}$, aumento del desempleo y descenso económico ${ }^{15}-$ y que pusieron en duda la efectividad de las políticas keynesianas, las de mayor reputación en esa época. La estanflación unida a la sensación de ir perdiendo la carrera política y económica con el socialismo de Estado crearon las condiciones para que las autoridades económicas y muchos integrantes de los centros de investigación teórica y aplicada de los países desarrollados impugnaran las hipótesis prevalecientes en el diseño y la ejecución de la política económica.

En ese ambiente objetaron, entre otras cosas, el Estado de Bienestar, la intervención estatal en la producción de bienes y servicios, las políticas económicas de objetivo flexible y la creencia en que los agentes económicos se acomodaban en forma pasiva a las políticas del gobierno. Pusieron en duda la eficacia de las políticas keynesianas y desacreditaron el efecto multiplicador del gasto público. En el orden de preferencias de los críticos, la eficiencia era el criterio más valorado y se convirtió en el objetivo primordial de la política económica, pues parecía ser el mejor instrumento para alcanzar y superar a las economías socialistas.

En la búsqueda de eficiencia, desde finales de los años setenta y en los ochenta los gobiernos de los principales países desarrollados iniciaron el desmonte del Estado con la privatización de empresas

\footnotetext{
${ }^{13}$ Goode (1993) analiza el contexto, las tendencias y resultados de las misiones de asesoría tributaria a los gobiernos de América Latina, Asia y África en los años ochenta.

${ }^{14}$ En 1970 Estados Unidos tuvo una inflación anual del 5,6\% y en 1980 del $12,4 \%$, según datos de la FRB.

${ }^{15}$ Estados Unidos creció a una tasa del 2\% anual en 1970 y a una de $-2 \%$ en 1980, según datos del Departamento de Comercio (NIPA Table).
} 
estatales, la desregulación, la profundización de la apertura de la cuenta de capital y la modificación radical de la política tributaria. Se vivía en la época de la reaganomics, llamada así por las políticas económicas implantadas por el Partido Republicano en Estados Unidos y el Partido Conservador en el Reino Unido, durante los gobiernos de Ronald Reagan y Margaret Thatcher. La nueva política hacía parte integral de lo que se llamó nuevo orden económico mundial ${ }^{16}$.

En el mundo académico despuntaba el enfoque de expectativas racionales, y la investigación se desplazó a la micro-fundamentación de la macroeconomía ${ }^{17}$. El resultado fue el predominio, desde los años ochenta, de la teoría nueva-nueva clásica en investigación básica y en el diseño y ejecución de la política económica. En forma esquemática se puede decir que esta escuela adopta micro-fundamentos basados en una estructura de mercado de competencia perfecta, considera independientes las dimensiones monetaria y real, y no da espacio a la política fiscal. La opción alternativa eran los nuevos keynesianos ${ }^{18}$, cuya micro-fundamentación parte de una estructura de mercado oligopólica; que, postulan una relación fuerte entre dinero y mundo real y dan espacio a la acción fiscal. También hay que señalar un cambio significativo en la economía del bienestar: a la visión tradicional se opuso la nueva teoría del bienestar ${ }^{19} \mathrm{y}$, en el nuevo siglo, la economía del bien-estar o estar bien.

A la par, en la discusión macroeconómica se impuso a mitad de los años ochenta el concepto de desarrollo como crecimiento y se dejó atrás la polémica sobre los modelos clásicos de Solow y de HarrodDomar. Se abrió paso la teoría del crecimiento endógeno y, desde luego, se alteraron algunas preguntas del programa de investigación de Solow y surgieron otras nuevas. En el tema que nos atañe se destacan tres modificaciones. Primera, el núcleo de la investigación del crecimiento endógeno excluye la relación entre distribución de la riqueza y crecimiento económico. Dada la distribución inicial, que no es el problema, se explora el efecto del capital humano y el desarrollo técnico-científico sobre la tasa de crecimiento, que sí es el problema. Obviamente, cabe preguntar si una teoría del largo plazo

16 Para una delimitación de ese nuevo orden ver Portales (1983).

17 Para los argumentos básicos, ver Mankiw y Romer (1991), Miller (1994), Snowdon y Vane (1997), Jenkinson (2000), Backhouse y Salanti (2000) y Drèze (2001). La recapitulación del cambio de paradigma se compiló en el Journal of Money, Credit and Banking 20, 3, 1988, en especial en los artículos de Mankiw, McCallum y Kotlikoff.

${ }_{18}$ Galí (2008) presenta en forma rigurosa las diferencias entre nuevos-nuevos clásicos y nuevos keynesianos.

${ }_{19}$ Para una síntesis de la nueva teoría del bienestar, ver Stiglitz (1994). 
puede excluir los efectos de la distribución sobre la demanda y, con ellos, sobre el crecimiento. Segunda, en política económica se empezó a hacer énfasis en el largo plazo, donde el crecimiento se basa en la inversión privada en capital humano. Este argumento se opuso a las viejas políticas keynesianas de gasto de corto plazo. Tercera, muchos investigadores equipararon desarrollo a crecimiento y hoy es de nuevo necesario hacer una síntesis (Ros, 2004).

Salvo pocas excepciones, la mayoría de los modelos de crecimiento endógeno dejan por fuera la política fiscal, con lo cual niegan la posibilidad de alterar la distribución del ingreso en función del desarrollo y la equidad social. Algunos, cuando la incluyen, sugieren que una política fiscal óptima es aquella en la que, en el largo plazo, el impuesto a los ingresos del capital es cero; el gasto público se financia con impuestos proporcionales a la renta del capital y al ingreso al trabajo; $y$ en el estado estacionario el impuesto óptimo al capital puede ser positivo, pero si es nulo el modelo alcanza su nivel óptimo (Chari y Kehoe, 1999).

Vale la pena hacer un paréntesis para señalar que algunos investigadores se hicieron una pregunta que no hace parte del núcleo de investigación de la teoría del crecimiento: ¿hay convergencia económica entre tipos de países? Y no es del núcleo de investigación porque los modelos de crecimiento se preguntan por la convergencia de una economía hacia una ruta de crecimiento estable y en equilibrio, con independencia de la razón capital-trabajo inicial, algo totalmente diferente de la pregunta que se hacen quienes investigan la convergencia económica entre países o regiones, desde el trabajo pionero de Barro y Sala-i-Marti (1990 y 1991). Estos últimos investigan en torno a la velocidad de convergencia en el crecimiento de los ingresos o $\beta$-convergencia entre regiones o países pobres y países ricos.

Retomando el tema, durante la década de los setenta los trabajos teóricos sobre el impuesto óptimo de Mirrlees (1971), Diamon y Mirrlees (1971 a y 1971b), y los aportes de Sandmo, Atkinson, Rosen, Stern, Feldstein y Brandford, entre otros, lo elevaron a paradigma en teoría impositiva. En congruencia con los cambios en la visión macroeconómica, en teoría de la hacienda pública se desplazó el núcleo de investigación de la hacienda funcional tipo Musgrave a la teoría de la elección pública tipo Buchanan. Y de manera congruente con las exigencias teóricas de los micro-fundamentos, en los años ochenta la teoría del impuesto óptimo se tomó el programa de investigación $\mathrm{y}$ con base en ella se diseñaron muchas reformas tributarias.

La teoría del impuesto óptimo sugiere que la mejor estructura tributaria es aquella en que el planificador maximiza la función de 
bienestar social (¡el agregado de utilidades individuales!). Si el planificador no tiene restricciones para elegir entre estructuras impositivas alternativas y no existen diferencias significativas en la capacidad de pago de los contribuyentes, el impuesto óptimo es aquel que minimiza las distorsiones en el mercado, es decir, que no altera el precio relativo de los bienes y servicios y, por tanto, tampoco la asignación eficiente de recursos. El impuesto que cumple esa condición es lineal, impuesto de tarifa única (flat tax en teoría hacendística) o impuesto general o de suma fija (lumpsum tax en teoría económica). La tributación de suma fija se limita a aplicar un tipo impositivo a todos los bienes y servicios que se consumen o a gravar con la misma tarifa la renta o la riqueza de todos los ciudadanos. No admite exenciones ni exclusiones.

La decisión de política se limita a definir la base impositiva: gravar la renta consumida o la renta generada o ambas. Con supuestos muy restrictivos -o alejados de la vida práctica- el impuesto óptimo tipo Mirrlees (1971) logra equidad sin costos de eficiencia, pues no desincentiva a los individuos ricos para que produzcan más. En la teoría del impuesto óptimo no desincentivar a los individuos de rentas altas con impuestos implica que el Estado elige la tarifa impositiva marginal donde obtiene el recaudo máximo de estos individuos; es decir, bajo los supuestos de la curva de Laffer, a partir del monto óptimo de recaudo la tarifa impositiva para los más ricos es cero. Como señalan Mankiw et al., los resultados a los que llega esta teoría desconciertan a comentaristas y autoridades económicas:

1) las tarifas impositivas marginales óptimas dependen de la distribución de la capacidad imponible; 2) las tasas impositivas marginales óptimas podrían disminuir en las rentas altas; 3 ) un impuesto de suma fija, con una transferencia universal de suma fija, podría ser una situación casi óptima; 4) el grado óptimo de redistribución aumenta con la desigualdad de salarios; 5) los impuestos deberían depender de las características personales, así como de los ingresos; 6) sólo los bienes finales deberían estar sujetos a impuestos, y en general, habría que gravar estos bienes de manera uniforme; 7) la renta del capital no debería estar sujeta a impuestos, al menos mientras sea una expectativa; y 8) en las economías dinámicas estocásticas, la política impositiva óptima exige un nivel de complejidad cada vez mayor (Mankiw et al., 2009).

Así, desde los años setenta, tanto en política económica como en teoría económica se pasó del enfoque de demanda keynesiano a otro que ponía de relieve la oferta, de ahí su nombre: ofertismo. Un resultado práctico importante de este enfoque fue la reforma tributaria de 1986 en Estados Unidos, parte central de la política Reagan. Con ella se finiquitó la época en que la estructura tributaria estaba dominada por impuestos directos, en especial al capital, y se inauguró la actual, donde la carga tributaria recae principalmente en el consumo, se reducen 
las tarifas marginales a la renta, se unifican las tarifas impositivas $y$ se amplía la base gravable ${ }^{20}$.

En el ambiente de estanflación de los años setenta hubo dos choques petroleros (1973-1974 y 1979-1980) y un choque cafetero (1976-1979) que produjeron ingresos extraordinarios a muchos países subdesarrollados. Esos choques de precios tuvieron tres consecuencias importantes para sus economías. Primera, en algunos países se inició una apertura comercial para acelerar la industrialización mediante la competencia internacional y evitar los efectos cambiarios, monetarios e inflacionarios de los excedentes del comercio internacional ${ }^{21}$. Segunda, ante el volumen de recursos inesperados los gobiernos no tuvieron necesidad de modificar las tarifas impositivas ni las bases tributarias, pues además de los ingresos del choque obtenían crédito para financiar el gasto. Y tercera, la banca internacional tenía abundantes recursos, provenientes de las bonanzas petroleras, y parte de ese exceso lo prestó a gobiernos latinoamericanos; la región tuvo un boom de financiación externa, en especial los tres países más grandes. En ese momento se tenía la sensación de que por fin se superaba la restricción de ahorro para el desarrollo que tanto se discutió en las décadas anteriores.

En América Latina, después del primer choque petrolero se replanteó el modelo de industrialización y crecimiento. La idea era aprovechar ventajas comparativas en el comercio internacional para lograr un cambio estructural. Es decir, pasar de una economía relativamente protegida a una más abierta. Algunos países acogieron esta política, primero los del Cono Sur, en especial Chile ${ }^{22}$. Con las bonanzas de precios de bienes primarios el tema tributario quedó marginado. La sociedad política o Estado se limitó a profundizar la institucionalización de impuestos a las ventas, que en algunos países se implantaron en los años sesenta, y a corregir las pérdidas por inflación ${ }^{23}$, un aspecto que ya habían advertido el trabajo pionero de Olivera (1967) y los análisis de Aghevli y Khan (1977) y Tanzi (1978), que dieron origen al llamado "efecto Olivera-Tanzi"24.

${ }^{20}$ Ballentine (1992) evalúa la reforma tributaria mencionada y Mirrlees et al. (2010) analizan las consecuencias y tendencias futuras de las políticas del Reino Unido.

${ }^{21}$ En algunos países hubo una desindustrialización causada por la enfermedad holandesa creada por el choque de divisas.

${ }^{22}$ Para un examen de este caso, ver Edwards y Cox (1986).

${ }^{23}$ Chile fue el primer país de América Latina que empezó a corregir los efectos inflacionarios, desde los años cincuenta; en los setenta profundizó el proceso.

${ }^{24}$ En presencia de inflación, normalmente inducida por el financiamiento monetario del gobierno ante la baja tributación, hay una pérdida real en el recaudo 
La deuda externa y el flujo de divisas de los años setenta se agotaron, y durante su existencia transitoria los gobiernos adoptaron un patrón de gasto público que luego fue imposible de sostener. En los primeros años ochenta, el entorno se caracterizaba por regímenes cambiarios controlados, sistema financiero interno reprimido, alto desempleo de factores y acelerada inflación. Sin recursos disponibles, se inició una etapa con tasas de crecimiento económico bajas y falta de arbitrios fiscales corrientes que les permitieran responder por sus obligaciones externas, y en algunos países se inició un proceso hiperinflacionario. Estas dificultades condujeron al estallido de la crisis de la deuda mexicana en 1982.

Cuando México declaró la moratoria se hizo evidente la incapacidad de las economías subdesarrolladas para generar ingresos tributarios que sufragaran el pago del servicio de la deuda externa pública y de la deuda privada que los gobiernos terminaron por asumir al ofrecer garantías a la banca internacional para que otorgara créditos a los empresarios ${ }^{25}$. Con la crisis de los años ochenta llegó la época de los ajustes y la estabilización macroeconómica ${ }^{26}$, y los gobiernos perdieron el poco margen de libertad que tenían para diseñar en forma autónoma la política económica. En efecto, el ajuste y la estabilización llegaron en el momento en que dominaban la reaganomics, la teoría nueva-nueva clásica, la teoría del crecimiento endógeno, la teoría del impuesto óptimo, la teoría de la elección pública, y en que empezaba a ejercer presión política y técnica lo que se llegó a llamar Consenso de Washington.

Los organismos multilaterales y los centros de pensamiento empezaron a pregonar que el ajuste macroeconómico eficiente y eficaz era aquel que abandonaba el modelo de crecimiento con intervención estatal e industrialización inducida; en otras palabras, ajuste y estabilización significaban privatizar, liberar la balanza de pagos e implantar un régimen cambiario libre ${ }^{27}$. En América Latina, Chile se elevó a paradigma de política económica, donde esa política se empezó a implantar desde mediados de los años setenta.

causada por el lapso entre el momento de generar el hecho imponible y el período de liquidación y pago, durante el cual opera la inflación.

${ }^{25}$ Para una visión panorámica del endeudamiento latinoamericano, ver Bianchi (1985), Thorp y Whitehead (1986) y Ffrench y Feinberg (1986).

${ }^{26}$ Algunos estudios de los programas de ajuste y estabilización en América Latina se encuentran en Edwards y Teitel (1986), Griffith (1988), y en los artículos de la edición especial de la Colección de Estudios CIEPLAN, No. 23 de 1988.

${ }^{27}$ Entre los trabajos a este respecto se destacan los de Seade (1990), Reisen (1990), Blejer y Cheasty (1990) y Tanzi (1990). 
Empezó a descollar la opinión según la cual el atraso económico era causado por la represión del mercado y, en consecuencia, se argumentaba que si se liberaban las fuerzas del mercado habría una mayor tasa de crecimiento que se irrigaría por toda la sociedad y, por medio de un mecanismo no descrito, se lograría una mejor situación social. En esos momentos, en la llamada situación social de los países, si bien se discutía sobre la distribución del ingreso ${ }^{28}$, aún no había tomado fuerza el concepto de pobreza en la discusión teórica y política, lo que estaba reservado para los años noventa y la década siguiente. En esta primera década de siglo, la ausencia del tema de la distribución en la discusión de teoría económica se ha mitigado debatiendo la relación entre crecimiento, pobreza e instituciones ${ }^{29}$ que apoyan al crecimiento (Meir y Stiglitz, 2001, y Sen, 1999). Al tema de pobreza se le ha dado autonomía relativa, ahora la pobreza es mucho más que distribución, es una visión multivariada o, con el término más utilizado, multidimensional. Desde luego, la perspectiva de la nueva teoría del desarrollo no está unificada y existen visiones latinoamericanas alternativas (Ocampo, 2004).

La nueva visión señala un aspecto importante para América Latina: el desarrollo visto como crecimiento se impuso sobre las demás hipótesis, justo cuando se argumentaba que el subdesarrollo es un fenómeno complejo "de carácter dinámico que abarca elementos técnicos, económicos, sociales, políticos y culturales”(Prebisch, 1979). Desde los años noventa prácticamente se clausuraron los análisis y debates en torno a la dependencia, la industrialización, la relación centro-periferia, el desarrollo como etapa, el desarrollo como proceso, el capitalismo tardío, el imperialismo, el proceso político, etc. Esos conceptos quedaron proscritos del vocabulario de los académicos y de los diseñadores y ejecutores de política económica y social.

Pese a su expulsión de las escuelas de economía y centros de pensamiento latinoamericanos, las viejas categorías de la CEPAL fueron retomadas e integradas a la agenda de investigación en el mundo académico de los países desarrollados. Después de Krugman (1979), que retomó el concepto de centro-periferia y lo incorporó en modelos norte-sur para explicar la localización industrial en el marco de la teoría del comercio internacional, en los años noventa resurgió la economía regional y urbana o nueva geografía económica ${ }^{30}$. Los trabajos de P.-R. Ágenor, H. Chenery, R. Dornbusch, P. J. Montiel, S. Robinson, M. Syrquin, en el Fondo Monetario Internacional (FMI)

${ }_{28}^{28}$ Para una selección de las investigaciones de esa época, ver Foxley (1974).

${ }^{29} \mathrm{Las}$ reglas formales e informales que imperan en una sociedad.

${ }^{30}$ Para una síntesis de esta temática, ver Fujita y Thisse (2002). 
y en el Banco Internacional de Reconstrucción y Fomento (BIRF), y los de L. Taylor y W. Buiter en la academia, llevaron al núcleo de la interpretación de la dinámica del subdesarrollo los conceptos de tipo de estructura económica y términos de intercambio y, con ello, dieron vida a la nueva macroeconomía del desarrollo, que el trabajo de Agénor y Montiel (2008) expuso en forma coherente y sintética.

Mientras que, conforme a la visión macroeconómica vigente, investigadores, misiones nacionales e internacionales, centros de estudio y autoridades económicas sostenían que la intervención del Estado en la producción de bienes y servicios se debía desmontar, que el desarrollo debía ser impulsado por las fuerzas del mercado, era congruente que en la teoría y la práctica de la tributación en países subdesarrollados se buscara minimizar los efectos distorsionantes sobre los mercados y sobre variables macroeconómicas fundamentales como la tasa de interés, la tasa de cambio y el costo de uso del capital (Blejer y Chu, 1989; Ahmad y Stern, 1991; Bird, 1992, y Tanzi, 1984, 1986 y 2004). Minimizar el exceso de carga tributaria y las distorsiones equivalía a dar a la eficiencia impositiva un rango superior a cualquier otro criterio económico y social, en países que mostraban profundas brechas de ingresos entre sus habitantes. Siguiendo el enfoque de ofertista y con el impuesto óptimo como principio teórico rector se iniciaron nuevas reformas tributarias en el mundo subdesarrollado desde mediados de los años ochenta (Ghandi, 1987).

En el contexto de estabilización y ajuste, muchos gobiernos y congresos latinoamericanos, en forma autónoma o por exigencia de misiones internacionales, hicieron reformas tributarias cuyo objetivo era reducir la complejidad, ineficiencia e inestabilidad de las estructuras impositivas vigentes ${ }^{31}$. A diferencia de los años cincuenta y sesenta, cuando se buscó profundizar el sistema impositivo personal y dar mayor importancia a los impuestos de renta y patrimonio -política que ayudó a reducir la dependencia del recaudo del comportamiento externo-, desde el primer lustro de los ochenta la nueva política tributaria dio prelación a los impuestos indirectos (Emran y Stiglitz, 2005), en especial se pasó del impuesto a las ventas al impuesto al valor agregado (IVA); el primer país que lo introdujo en América Latina fue Chile en 1975.

Se institucionalizó la lógica del impuesto óptimo y, desde 1987, se hicieron reformas tributarias a la Reagan por el efecto de contagio de

${ }^{31}$ Para una revisión de las reformas tributarias de los años ochenta, ver Bird (1992), Bird y Casanegra (1992) y Ahmad y Stern (1989 y 1991). Para los objetivos y una visión panorámica, Goode (1993); para las metas y especificaciones técnicas, Gray (1989). 
las políticas del mundo desarrollado, por exigencia del FMI y el BIRF en sus programas de ajuste macroeconómico para dar acceso a crédito externo nuevo, y porque los integrantes de los centros de pensamiento locales y los funcionarios encargados de las políticas económicas en estos países se educaron en los preceptos de la nueva teoría económica y los pusieron en práctica sin beneficio de inventario. En este sentido, el razonamiento que se siguió en política económica no fue neutral, estaba en línea con las creencias y los intereses políticos y económicos de los gobiernos de los países desarrollados, y fue parte integral de la visión de una economía mundial que debía sostenerse conforme a los argumentos de la economía de la oferta.

Las personas que hacían investigación básica sobre el impuesto óptimo en países subdesarrollados, no los gobiernos y centros de pensamiento locales, tenían claro que se debía modificar el principio rector para incorporar las características distintivas de sus economías, como el mal funcionamiento de los mercados; el gran peso del sector primario en la estructura productiva; el dualismo, en especial la informalidad en los mercados laboral y financiero, y los efectos de choques en los términos de intercambio, entre otros temas (Newbery y Stern, 1987, y Burguess y Stern, 1993). La informalidad como fuente de baja recaudación, o sector de difícil recaudo, se convirtió en un tema especializado, tanto en la investigación teórica como en la conducción de la política tributaria ${ }^{32}$. La teoría sugiere que la informalidad tiene efectos importantes y diferentes según si el impuesto es directo o indirecto (Gordon y Li, 2005a y 2005b). En estos primeros años de siglo ese tema se tornó crucial para la estabilidad financiera del gobierno en los países subdesarrollados, en especial de los que hicieron profundas reformas de la seguridad social y los beneficios de la asistencia pública: ¿cómo convertir a los trabajadores y empresarios informales en cotizantes de los regímenes pensionales?, ¿cómo reducir la evasión tributaria que usa la informalidad como fachada?

Así, en los años ochenta hubo un cambio casi imperceptible en las inclinaciones de los estudios sobre tributación. En el día a día se invirtió la dirección de las causas, se relegaron las investigaciones que se dedicaban a la vieja cuestión de los determinantes estructurales del recaudo, y despuntaron los estudios que medían los efectos de la tributación sobre las demás variables económicas para sugerir políticas que minimizaran su impacto sobre los mercados. Entre los pocos que

${ }^{32}$ Ver Arachi (2007), Piggott y Whalley (2001), Emran y Stiglitz (2005), Keen (2007), Alm y Martínez (2003), Araújo y Chambas (2003), Bird y Wallace (2003), Engelschalk (2003), Romanov (2003), Thuronyi (2003), Mitra y Stern (2003) y Wallace (2002). 
perseveraron en la inelasticidad ingreso del recaudo en estos países se encuentra Tanzi (1988 y 1989).

El diseño de normas tributarias en los años noventa y la década siguiente obedeció a los parámetros internacionales trazados para economías desarrolladas y a los lineamientos centrales de los programas de ajuste y apertura de los ochenta:

1. La apertura económica, política esencial del ajuste, implicaba por definición el desmonte de los aranceles para modificar las tasas relativas de protección sectorial y obligar a los empresarios a elevar la productividad y lograr una asignación eficiente de recursos. El menor recaudo que envolvía dicha política se asimiló a un costo fiscal de corto plazo pues, a largo plazo, lo compensarían las mayores tasas de crecimiento económico, que elevarían el recaudo (Tanzi, 2004). Las evaluaciones muestran que esta modificación implicaba transformar toda la estructura tributaria y dirigirla hacia impuestos internos de "difícil recaudo" e implementación como el impuesto de renta (Aizenman y Jinjarak, 2009).

2. Con el cambio en el modelo de acumulación, la estabilidad fiscal se garantizaba con ajustes en el gasto, privatizaciones, impuestos a la actividad económica interna más dinámica y medidas compensatorias específicas de la reducción de aranceles (Cuddington, 1988; Tanzi y Zee, 2001, y Talvi y Végh, 2000).

3. La privatización de los activos públicos implicaba que el Estado tenía que ser Estado $^{33}$ : obtener recursos financieros mediante la tributación y no como empresario rentista, es decir, recomponer el total de ingresos públicos reduciendo la participación de los ingresos no tributarios y aumentando la de los tributarios; para ello debía ejercer su poder de monopolio impositivo. La promesa era que la venta o concesión de activos estatales desmontaría el flujo de rentas y las ineficiencias en la producción del bien o servicio monopolizado, y a cambio obtendría un flujo de recaudo por impuesto de renta e IVA. Como complemento fundamental de la privatización, y para el éxito del proceso, había que implantar un Estado regulador de los monopolios naturales y promotor de la competencia. Obviamente, el ideal del Estado regulador dependía de la capacidad de la sociedad para evitar que el Estado fuera capturado por los intereses económicos más poderosos.

4. Los gobiernos continuaron el proceso de simplificación de los procedimientos de administración tributaria, que se inició a mediados

\footnotetext{
${ }^{33}$ Para un análisis comparativo de la privatización en Colombia, ver Hernández (2004).
} 
de los años ochenta; se redujeron el número de tarifas que tenía un mismo impuesto ${ }^{34} \mathrm{y}$ el número de contribuyentes obligados a presentar declaración de impuestos.

5. Se amplió la base del IVA y se recompuso la carga tributaria hacia los consumidores, con lo cual se redujo la tributación de la renta de las empresas ${ }^{35}$.

6. La recomposición de la tributación en favor del capital ignoró las conclusiones de estudios econométricos que indicaban que el efecto de la tributación en el costo de uso del capital era mínimo; tampoco se tomaron en cuenta las evaluaciones de la reforma de Estados Unidos que señalaban que los resultados no fueron los que se usaron como argumentos para llevar a cabo la reforma, o que sus efectos eran muy cuestionables (Ballentine, 1992).

7. Los asesores que propusieron reducir el impuesto de renta y los Estados de los países que adoptaron esta medida suponían que los contribuyentes pagaban una tarifa superior a la óptima en impuestos directos. Siguiendo el planteamiento de la curva de Laffer, asesores y Estados esperaban que si se reducía la tarifa marginal del impuesto de renta el ingreso tributario crecería, y el bienestar social aumentaría. No sobra decir que fueron pocos los estudios sobre las tarifas efectivas vigentes en el mundo subdesarrollado y que, por tanto, las reducciones del impuesto de renta se decidieron por intuición, no por medición.

$\mathrm{Si}$ a mediados del siglo XX se decía que las estructuras tributarias del subdesarrollo dependían de la tributación a la actividad económica externa $^{36}$, en los años noventa, con las reformas arancelarias, llegó el momento de demostrar si la fiscalidad podía o no desvincularse de los choques externos, y si en la estructura tributaria aumentaba o no el peso específico de la imposición a la actividad económica interna. Si la discusión inicial fue sobre cómo hacer tributar al capital y cómo contribuía la tributación a mayores niveles de desarrollo, desde los noventa la cuestión es la de cómo reducir la presión fiscal a la inversión privada y elevar la tasa de crecimiento de largo plazo.

Los resultados de las evaluaciones de las reformas tributarias de los años ochenta y los noventa revivieron, desde finales del siglo pasado, el interés por la imposición en el subdesarrollo. Desde luego, los nuevos estudios se realizan en un medio histórico y académico distinto, que indica el perfil de las investigaciones. Por ejemplo, hubo

${ }^{34}$ Tanzi (1987) muestra la dispersión de tarifas en los países subdesarrollados.

${ }^{35}$ Carciofi et al. (1994) hacen un análisis global de las reformas tributarias en América Latina durante los años ochenta.

${ }^{36} \mathrm{O}$ índice de dependencia fiscal externa medido por los impuestos a las importaciones y las exportaciones con respecto al ingreso tributario total. 
avances económicos y políticos significativos en muchos países, especialmente en el Sudeste Asiático y América Latina. El FMI creó incluso una nueva clasificación en la que algunos son catalogados como economías emergentes. $\mathrm{Y}$ en lo conceptual, con trabajos como los de Alesina, Rodrik, Tabellini, etc., se incorporaron de forma más robusta al cuerpo de la teoría económica las variables institucionales que dieron otra perspectiva al análisis de la política en economía.

Las conclusiones a las que llegan las nuevas disertaciones con técnicas econométricas más refinadas no distan de las de mediados del siglo: los países subdesarrollados tienen una presión tributaria y tarifas impositivas bastante menores y dispersas que las de los países desarrollados (Gordon y Li, 2005a y 2005b, y Norregaard y Khan, 2007); no hay relación directa entre recaudo e ingreso nacional, o elasticidad ingreso baja (Mkandawire, 2010); continúa la dependencia del recaudo con respecto al comercio exterior (Adam et al., 2001, y Baunsgaard y Keen, 2005); en los más subdesarrollados la estructura tributaria aún cuenta (Stotsky y WoldeMariam, 1997); la corrupción y el régimen político determinan la presión fiscal (Cheibub, 1998; Ghura, 1998; Gupta, 2007, y Ehrhart, 2009). Este tipo de trabajos se inspira en argumentos sobre el cambio en las instituciones políticas, los conflictos distributivos entre agentes y demás desarrollos sobre el votante mediano, la agencia, el gorrón y la burocracia expuestos, entre otros, por Alesina y Rodrik (1994), Barro (1999) y Acemoglu y Robinson (2008).

En geopolítica se pasó, desde los años ochenta, del enfoque de mediados de siglo, cuando los antiguos países colonialistas se sentían políticamente comprometidos a ayudar a sus excolonias, como en el caso de África y Asia, a la idea de que cada quién debe asumir los costos de su desarrollo. En los últimos treinta años, la política de los países desarrollados hacia los subdesarrollados tiene como plataforma el aumento del crédito y, en su negociación, exigir mayor integración a los mercados mundiales y modificar las políticas macroeconómicas y sectoriales para garantizar el servicio de la deuda. En ese marco, la política tributaria queda sujeta a dos objetivos: lograr un volumen de recaudo que garantice el pago de los créditos y permitir mayor movilidad a los flujos de capitales desde los países desarrollados a los subdesarrollados. En la agenda de negociación, el interés de los primeros es el de armonizar la tributación de sus inversiones, en términos más claros, lograr menores tarifas del impuesto de renta.

Los estudios no dieron suficiente atención a la Realpolitik. Aunque Hinrichs (1967) ya lo había señalado, fueron Tanzi y Zee (2001), en 
una síntesis del problema de la tributación en países subdesarrollados, quienes nuevamente resaltaron los efectos sobre la imposición y la estructura tributaria de la captura del gobierno y el Congreso por parte de los propietarios de excedentes, o caudillismo que crea privilegios rentísticos en favor de los más ricos. Las investigaciones de los últimos veinte años se centran en el sistema político y de votación imperante en el subdesarrollo, sugieren que el nivel de recaudo y la facilidad para hacer reformas tributarias dependen de la presencia de democracia o autocracia, la rendición de cuentas y la transparencia fiscal (Bird et al., 2008); pero no tienen en cuenta quién ejerce el poder soberano, es decir, suponen que la vieja tesis de Adam Smith (1776) sobre la independencia entre poder político y poder económico es cierta y neutral para efectos fiscales ${ }^{37}$, o en otras palabras, que la participación individual en la riqueza social, la distribución, no se defiende en la arena política, peor aún si es el Estado el que se la quiere apropiar.

Al final de este recorrido por los últimos sesenta años de estudio y diseño de la tributación en países subdesarrollados se tiene que la teoría, hasta mediados de la década de los setenta, identificaba la inelasticidad del recaudo frente al ingreso nacional, sugería que la tributación limitaba el gasto público y por ende el desarrollo, y que dadas las características estructurales de sus economías la mayor carga tributaria debía recaer en el ingreso; en cambio, desde los años ochenta se relegó el tema de la elasticidad ingreso del recaudo y se pasó a sostener que la imposición no es óbice para el desarrollo, que el obstáculo es la intervención estatal, la cual debe disminuir, si no desaparecer, e incidir lo menos posible con impuestos en las asignaciones óptimas de los factores, que deben ser dictaminadas por las fuerzas del mercado. Por su parte, la política impositiva, hasta los años setenta, tuvo un carácter práctico pues seleccionaba los hechos generadores según la facilidad de recaudo, los costos de recaudo, la centralización administrativa, la estructura económica y, sobre todo, aquello que políticamente se podía hacer tributar $(\operatorname{tax} \text { handle })^{38}$; en cambio, desde los años ochenta se diseña y se ejecuta con el fin de reducir la tributación del ingreso, ampliar la base de impuestos al consumo, desmontar la protección arancelaria y dar descuentos y

\footnotetext{
37 "La riqueza, como dice Mr. Hobbes, es poder. Pero la persona que adquiere o hereda una gran fortuna no por eso adquiere necesariamente ni hereda poderío político, civil o militar" (Smith, 1776, cap. V, libro I, 32).

38 Estos argumentos fueron planteados, p. ej., por Martin y Lewis (1956), Hinrichs (1967) y Musgrave (1969), y se repiten parcialmente en Gordon y Li (2005a y 2005b).
} 
exenciones al capital o declarar no sujetas a las operaciones del capital para lograr mayores tasas de crecimiento económico.

\section{DIFERENCIAS EN LAS PREFERENCIAS TRIBUTARIAS}

Al comienzo, el debate sobre la tributación en el subdesarrollo enfocó el tema en torno a la relación entre volumen de recaudo y nivel de ingreso y, en las tres últimas décadas, en la tributación que minimiza el exceso de gravamen, en impuestos con efectos neutrales sobre los mercados. Ambos enfoques parten de la pretensión de ser capaces de generalizar ciertos hechos en unos pocos principios teóricos y, a partir de ellos, deducir preceptos positivos para diseñar y ejecutar la política impositiva. No obstante, al someter a pruebas estadísticas las hipótesis se encontraron anomalías que invalidaron, al menos parcialmente, la presunción de generalidad.

El resultado no podía ser otro, pues la introducción del concepto de desarrollo para hacer análisis comparativos implicaba diferencias de tiempo y lugar en el objeto de investigación, suponía reconocer implícitamente que existen diferencias cuantitativas y cualitativas significativas entre diferentes tipos de economía y que, por tanto, su historia y sus instituciones son esenciales para explicar el comportamiento tributario. En la primera década de este siglo, a nivel empírico se intenta avanzar introduciendo el proceso político y la cooptación del Estado por grupos de poder, con hipótesis ad hoc.

El desconocimiento histórico del proceso de formación del Estado indujo a los analistas a dejar al margen las preferencias del poder político con respecto a la exacción del excedente privado. La lectura de los escritos de quienes participaron en la controversia, o de artículos que recapitulan lo esencial, como los de Ahmad y Stern (1989) y Burgess y Stern (1993), lleva a deducir que partían de un supuesto implícito: el Estado en todo el mundo tiene la misma preferencia impositiva, prefiere más a menos tributos, y todos quieren llegar a la capacidad impositiva máxima ${ }^{39}$. Ese supuesto no es del todo razonable. La trayectoria del surgimiento de la sociedad politica, el Estado, fija los términos de su preferencia por el nivel de tributación.

La triada de países desarrollados -Estados Unidos, Europa y Japón $^{40}$ - tiene una historia político-tributaria parecida. En Europa y Japón ${ }^{41}$, la unificación del poder político en el Príncipe tuvo como

39 La capacidad impositiva máxima es aquella en que los costos sociales marginarles de los impuestos adicionales son mayores que los de deuda y emisión (Morag, 1973).

${ }^{40}$ Aquí Europa denota a Alemania, Inglaterra, Francia, Holanda y Bélgica.

41 Clark (1939), con base en un estudio de Kurt Singer, sostiene que en la 
base el monopolio de la fuerza armada y de la tributación, junto con la creación de una burocracia que ejercía el control sociopolítico (Anderson, 1996; Dobb, 1981; Elias, 1994; Kofler, 1971; Mann, 1986, y UNESCO, 1963). El Estado llevó al máximo la tributación con argumentos como la defensa externa, la administración de justicia y la expansión de su poder al resto del mundo; nivel de tributación que fue aceptado por la sociedad y que en los años ochenta llegó a representar el 50\% del ingreso nacional, en Francia y Alemania. Desde luego, hubo momentos en que la inequidad tributaria se hizo socialmente inaceptable y hubo revoluciones que modificaron la estructura tributaria, extendieron la base a quienes estaban exentos y cambiaron la dirección del gasto público, pero los niveles no se redujeron porque en el fondo se consideraba que con ello se pondría en peligro a la nación.

En Estados Unidos la situación fue diferente. En las trece colonias fundadoras la imposición seguía los pasos de la tradición inglesa. Los impuestos, aprobados por las asambleas locales, salvo los derechos de aduana, se aceptaron como elemento cardinal para el buen funcionamiento de la sociedad. La revolución de esas colonias no fue contra los impuestos al té y al papel sellado, sino en defensa de la autonomía del poder político local frente a la metrópoli (Bushnel, 2010, y Morison et al., 1999). Una vez las élites locales tomaron el poder político profundizaron las prácticas tributarias y las relaciones políticas: la representación política implicaba deberes ciudadanos con el fisco, y la defensa y construcción de la nación implicaba mantener y elevar la tributación heredada, como bien argumentaron sus fundadores (Hamilton et al., 1780).

E1 común denominador histórico en la triada desarrollada es la disposición de la sociedad política a cobrar el nivel máximo de tributos y usarlos en favor del desarrollo nacional (Mann, 1986). El cobro ganó legitimidad por la fuerza de la costumbre social y el uso que el Estado daba a los recursos. Las nuevas generaciones juzgan normal que el principe moderno reciba, en la primera década de este nuevo siglo, el 35\% del ingreso nacional, una tasa menor que las de épocas anteriores.

En cambio, en los países subdesarrollados el Estado surgió por el rechazo a una situación de dominio externo absoluto en lo econó-

primera mitad del siglo XIX en Japón sólo existía el impuesto a la agricultura, que cubría un $50 \%$ de la cosecha de arroz de regadío y un porcentaje algo menor en arroz de tierras altas. A finales del siglo XIX y comienzos del siglo XX se imponía una tarifa del $30 \%$ al ingreso agrícola neto. La tributación del comercio era esporádica. 
mico y en lo político. Las élites locales, la sociedad civil de la época ${ }^{42}$, pedían participación política a la metrópoli y rechazaron el pago de impuestos como cuota de protección ${ }^{43}$. Al no obtener respuesta favorable a sus demandas optaron por la independencia.

Los países que obtuvieron su emancipación con la guerra, como en América Latina, empezaron a ser y hacer lo contrario de lo que siempre propugnaron. En el momento de asumir la soberanía, cuando las élites se deben convertir en Estado, decidieron aplicar la capacidad impositiva mínima porque percibían los tributos como vasallaje político. Se negaron, contradictoriamente, a utilizar el fundamento financiero de su poder político. Las élites no comprendieron que ya no eran sociedad civil y que, convertidas en Estado, debían asumir responsabilidades políticas y sociales que requerían una fuerte financiación tributaria, pues partían de unas finanzas públicas en cero, en el mejor de los casos, o en rojo por la deuda externa que financió las guerras de independencia.

Además, quienes se constituyeron en sociedad política fueron incapaces de revertir la cultura de incumplimiento de las obligaciones tributarias que sembraron en la época colonial, como expresión del rechazo al dominio político y de la desconfianza a priori hacia el Estado. En algunos países se reforzó incluso socialmente la tendencia a evadir por la desconfianza que sembraron quienes empezaron a detentar el poder político o porque los contribuyentes simplemente percibieron que los grupos económicos poderosos habían capturado el poder político.

Allí donde las colonias recibieron pacíficamente el poder de una metrópoli en retirada, sin un grupo dominante en la población, entraron en conflicto etnias, minorías privilegiadas o grupos regionales por centralizar el poder político, como en algunos países africanos. En esos países, la falta de un Estado unificado, además de ser signo de subdesarrollo, es un impedimento para lograr mayores recaudos.

La estructura tributaria se empezó a transformar en el mundo subdesarrollado desde el momento de la independencia, en medio de disputas políticas que surgieron por la colisión entre las necesidades de la construcción de los nuevos Estados y el rechazo de la tributación, y la capacidad impositiva se modificó de acuerdo con el grado de

\footnotetext{
${ }^{42}$ Se utiliza el concepto de sociedad civil y sociedad política conforme al modelo de Hegel, que se analiza en Bobbio y Bovero (1994).

${ }^{43}$ En economía política, un impuesto se puede considerar como el pago de la cuota por pertenecer al Estado o por asegurar la integridad física y patrimonial (prima de seguro) o como el precio que pagan los individuos por los bienes públicos.
} 
maduración del Estado, la estabilidad macroeconómica y los intereses políticos de corto y largo plazo de los bloques en el poder ${ }^{44}$.

\section{CONCLUSIONES}

La anomalía de la elasticidad del recaudo tributario con respecto al ingreso nacional en países subdesarrollados originó un programa de investigación que buscaba dilucidar esa irregularidad introduciendo argumentos históricos, variables institucionales y reformulaciones teóricas. En las explicaciones de los últimos sesenta años influyen los cambios sociales, políticos y económicos mundiales que han ocurrido en este período.

Las políticas tributarias que adoptaron los países subdesarrollados fueron diseñadas, primero, con base en teorías que trataron de incorporar sus características económicas y sociales pero luego, desde los años ochenta, en teorías y políticas de países desarrollados, así se reconocieran las sustanciales diferencias entre ambos tipos de países. Las nuevas políticas tributarias se implantaron por el efecto de copia, las imposiciones de organismos multilaterales y la aceptación teórica, sin beneficio de inventario, de individuos educados en el Primer Mundo que desempeñaban funciones públicas o eran asesores del gobierno o, simplemente, vendedores de ideas a la clase dirigente.

En la discusión se dio por sentado que la preferencia de los Estados por la tributación es idénticamente compulsiva. No se tuvo en cuenta que en el mundo subdesarrollado la sociedad política es aversa a la tributación porque en su origen y configuración se opuso a los tributos. Esa propensión obligó a diversificar las fuentes de financiación y a mantener una presión tributaria que combina impuestos con actividad empresarial, deuda y emisión.

E1 desconocimiento del elemento político en el proceso de formación del Estado lleva a ignorar buena parte de las causas que explican la trayectoria de las decisiones sobre qué se grava (base), cuánto se paga (tarifa) y quién paga (contribuyente), por tanto, sobre el volumen efectivo de recaudo y su relación con el ingreso. La importancia de este punto en discusión se ha de comprobar país por país o por grupos homogéneos de países. Como continuación de este artículo se abordará el caso colombiano en una próxima publicación.

Si el objetivo inicial era reformar la tributación en los países subdesarrollados para el avance económico y social, hoy la pregunta es: ¿cuánto contribuyó la política impositiva a lo que hoy son estos países? La respuesta abre nuevas rutas de investigación pues lleva a

${ }^{44}$ El tema se ilustra en Cheibub (1998) y Kenny y Winer (2001). 
explorar el efecto fiscal global sobre el desarrollo, es decir, si la tributación, el gasto público y la deuda estatal permitieron crear mercados e instalar infraestructura pública, si la justicia garantizó los derechos de propiedad y por ende las transacciones en los mercados; en suma, si la consolidación del Estado es fundamental para el desarrollo económico y social.

\section{REFERENCIAS BIBLIOGRÁFICAS}

1. Acemoglu, D. y J. A. Robinson. "Persistence of power, elites, and institutions”, American Economic Review 98 1, 2008, pp. 267-293.

2. Adam, C. S., D. L. Bevan y G. Chambas. "Exchange rate regimes and revenue performance in Sub-Saharan Africa", Journal of Development Economics 641, 2001, pp. 173-213.

3. Agénor, P. R. y P. J. Montiel. Development macroeconomics, $3^{\text {rd }}$ ed., Princeton, Princeton University Press, 2008.

4. Aghevli, B. B. y M. S. Khan. "Inflationary finance and the dynamics of inflation: Indonesia, 1951-72", American Economic Review 67, 3, 1977, pp. 390-403.

5. Ahmad, E. y N. Stern. "Taxation for developing countries", Handbook of Development Economics, vol. II, Amsterdam, Elsevier, 1989.

6. Ahmad, E. y N. Stern. The theory and practice of tax reform in developing countries, Cambridge, Cambridge University Press, 1991.

7. Aizenman, J. y Y. Jinjarak. "Globalization and developing countries: A shrinking tax base?", Journal of Development Studies 45, 5, 2009, pp. 653-671.

8. Alesina, A. y D. Rodrik. "Distributive politics and economic growth", The Quarterly Journal of Economics 109, 2, 1994, pp. 465-490.

9. Alm, J. y J. Martínez. "Sizing' the problem of the hard-to-tax", AYSPS Conference: The hard-to-tax, an international perspective, Atlanta, Georgia State University, 2003.

10. Anderson, P. El Estado absolutista, México, Siglo XXI, 1996.

11. Arachi, G. "Optimal origin-based commodity taxation in a small open economy", The B.E. Journal of Economic Analysis E Policy 7, 1, 2007.

12. Araújo, C. y G. Chambas. "Taxing the urban unrecorded economy in Sub-Saharan Africa", AYSPS Conference: The hard-to-tax, an international perspective, Atlanta, Georgia State University, 2003.

13. Backhouse, R. E. y A. Salanti, eds. Macroeconomics and the real world: Keynesian economics, unemployment, and policy, vol. II, Oxford, Oxford University Press, 2000.

14. Ballentine, J. G. "The structure of the tax system versus the level of taxation: An evaluation of the 1986 Act", The Journal of Economic Perspectives 6, 1, 1992, pp. 59-68.

15. Barro, R. J. "Determinants of democracy", Journal of Political Economy 107, 6, 1999, pp. S158-S183.

16. Barro, R. y X. Sala-i-M. "Economic growth and convergence across the United States", NBER Working Paper Series 3419, 1990. 
17. Barro, R. y X. Sala-i-M. "Convergence across states and regions", Brookings Papers on Economic Activity 22, 1, 1991, pp. 107-182.

18. Bauer, P. T. Crítica de la teoría del desarrollo, 1971, Barcelona, Orbis, 1985.

19. Baunsgaard, T, y M. Keen. "Tax revenue and (or?) trade liberalization”, IMF Working Paper 05/112S, 2005.

20. Bianchi, A., comp. La deuda externa latinoamericana, Buenos Aires, Grupo Editor Latinoamericano, 1985.

21. Bird, R. M. "Tax reform in Latin America: A review of some recent experiences", Latin American Research Review 27, 1, 1992, pp. 7-36.

22. Bird, R. M. y M. Casanegra. Improving tax administration in developing countries, Washington, IMF, 1992.

23. Bird, R. M. y O. Oldman. La imposición fiscal en los paises en desarrollo, México, UTEHA, 1967.

24. Bird, R. M. y S. Wallace. "Is it really so hard to tax the hard-to-tax? The context and role of presumptive taxes”, ITP Paper 0307, 2003.

25. Bird, R. M., J. Martínez-V. y B. Torgler. "Tax effort in developing countries and high income countries: The impact of corruption, voice and accountability", Economic Analysis and Policy 38, 1, 2008, pp. 55-71.

26. Blejer, M. y A. Cheasty. "Fiscal implications of trade liberalization", V. Tanzi, ed., Fiscal policy in open developing economies, Washington, IMF, 1990.

27. Blejer, M. y K. Y. Chu, eds. Fiscal policy, stabilization and growth in developing countries, Washington, IMF, 1989.

28. Bobbio, N. y M. Bovero. Sociedad y Estado en la filosofía moderna. El modelo iusnaturalista y el modelo hegeliano-marxiano, México, Fondo de Cultura Económica, 1994.

29. Buiter, W. H. "Structural and stabilization aspects of fiscal and financial policy in the dependent economy", Oxford Economic Papers 40, 1988, pp. 220-245.

30. Burgess, R. y N. Stern. “Taxation and development”, Journal of Economic Literature 31, 1993, pp. 762-830.

31. Bushnel, D. "Las independencias comparadas: las Américas del Norte y del Sur", Historia Crítica 41, 2010, pp. 20-37.

32. Carciofi, R., G. Barris y O. Centrángolo. Reformas tributarias en América Latina, Análisis de experiencias durante la década de los años ochenta, Santiago de Chile, CEPAL, 1994.

33. CEPAL. "Estudio económico de América Latina", Nueva York, E/ CN.12/164/Rev.1, 1949.

34. Chari, V. V. y P. J. Kehoe. "Optimal fiscal and monetary policy", Handbook of macroeconomics, vol. I, Amsterdam, Elservier, 1999.

35. Cheibub, J. A. "Political regimes and the extractive capacity of governments: Taxation in democracies and dictatorships", World Politics 50, 3, 1998, pp. 349-376.

36. Chenery, H. B. "Patterns of industrial growth", American Economic Review 50, 1960, pp. 624-654.

37. Chenery, H. B. y M. Syrquin. Patterns of development, 1950-1970, Oxford, Oxford University Press, 1975.

38. Clark, C. Las condiciones del progreso económico, Madrid, Alianza, 1939. 
39. Cuddington, J. "Fiscal policy in commodity-exporting LDCs", The World Bank Working Paper 33, 1988.

40. Diamond, P. y J. A. Mirrless. "Optimal taxation and public production I: Production efficiency", American Economic Review 61, 1, 1971a, pp. 8-27.

41. Diamond, P. y J. A. Mirrless. "Optimal taxation and public production II: Tax rules", American Economic Review 61, 3, 1971b, pp. 261-278.

42. Dobb, M. Estudios sobre el desarrollo del capitalismo, México, Siglo XXI, 1981.

43. Drèze, J. Advances in macroeconomic theory, New York, Palgrave, 2001.

44. Edwards, S. y A. Cox E. Monetarismo y liberalización. El experimento chileno, México, Fondo de Cultura Económica, 1986.

45. Edwards, S. y S. Teitel, comps. Crecimiento, reforma y ajuste. Las politicas comerciales y macroeconómicas de América Latina en los decenios de 1970 y 1980, Buenos Aires, Fondo de Cultura Económica y BID, 1986.

46. Ehrhart, H. "The political economy determinants of domestic tax mobilization in developing countries", Proceedings of the German Development Economics Conference, Frankfurt, Verein für Socialpolitik, 2009.

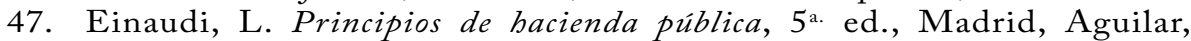
1958.

48. Elias, N. El proceso de la civilización. Investigaciones sociogenéticas y psicogenéticas, México, Fondo de Cultura Económica, 1994.

49. Emran, M. S. y J. E. Stiglitz. "On selective indirect tax reform in developing countries”, Journal of Public Economics 89, 4, 2005, pp. 599-623.

50. Engelschalk, M. "Creating a favorable tax environment for small business development in transition countries", AYSPS Conference: The hard-to-tax. An international perspective, Atlanta, Georgia State University, 2003.

51. Ffrench-D., R. y R. E. Feinberg, eds. Más allá de la crisis de la deuda. Bases para un nuevo enfoque, Buenos Aires, Grupo Editor Latinoamericano, 1986.

52. Foxley, A., comp. Distribución del ingreso, México, Fondo de Cultura Económica, 1974.

53. Fuentes, E. Las reformas tributarias en España. Teoría, historia y propuestas, Barcelona, Crítica, 1990.

54. Fujita, M. y J.-F. Thisse. Economics of agglomeration. Cities, industrial location, and regional growth, Cambridge, Cambridge University Press, 2002.

55. Furtado, C. Dialéctica del desarrollo. Diagnóstico de la crisis del Brasil, México, Fondo de Cultura Económica, 1965.

56. Galí, J. Monetary policy, inflation, and the business cycle: An introduction to the new Keynesian framework, Princeton, Princeton University Press, 2008.

57. Ghandi, V. Supply-side tax policy, its relevance to developing countries, Washington, IMF, 1987.

58. Ghura, D. "Tax revenue in Sub Saharan Africa: Effects of economic policies and corruption”, IMF Working Paper 98/135, 1998.

59. Goode, R. "Tax advice to developing countries: An historical survey", World Development 21, 1, 1993, pp. 37-53. 
60. Gordon, R. y W. Li. “Tax structure in developing countries: Many puzzles and a possible explanation", NBER Working Paper Series 11267, 2005a.

61. Gordon, R. y W. Li. "Puzzling tax structures in developing countries: A comparison of two alternative explanations", NBER Working Paper Series 11661, 2005b.

62. Gray, C. W. "Issues in income tax reform in developing countries", The World Bank Working Paper 267, 1989.

63. Griffith-J., S., comp. Deuda externa, renegociación y ajuste en la América Latina, México, Fondo de Cultura Económica, 1988.

64. Gupta, A. S. "Determinants of tax revenue efforts in developing countries", IMF Working Paper 07/184, 2007.

65. Hamilton, A., J. Madison y J. Jay. El federalista, 1780, México, Fondo de Cultura Económica, 1957.

66. Heller, J. y K. M. Kauffman. Incentivos fiscales para el desarrollo industrial, México, CEMLA, 1965.

67. Heller, W. W. "Políticas fiscales para los países subdesarrollados", 1954, R. M. Bird y O. Oldman, eds., La imposición fiscal en los países en desarrollo, México, UTEHA, 1967.

68. Hernández R., I. "Privatizaciones en Colombia", Apuntes del CENES 24, 37, 2004, pp. 55-92.

69. Hinrichs, H. H. Una teoría general del cambio de la estructura tributaria durante el desarrollo económico, México, CEMLA, 1967.

70. Jenkinson, T., ed. Readings in macroeconomics, Oxford, Oxford University Press, 2000.

71. Kaldor, N. "E1 impuesto sobe desembolsos en un sistema de imposición personal”, R. M. Bird y O. Oldman, eds., La imposición fiscal en los países en desarrollo, México, UTEHA, 1967.

72. Kalecki, M. Ensayos sobre las economia en vias de desarrollo, Barcelona, Crítica, 1976.

73. Keen, M. "VAT, tariffs, and withholding: Border taxes and informality in developing countries", IMF Working Paper 07/174, 2007.

74. Kenny, L. W. y S. L. Winer. "Tax systems in the world: An empirical investigation into the importance of tax bases, collection costs, and political regime", Carleton Economic Working Paper 01-03, 2001.

75. Kofler, L. Contribución a la bistoria de la sociedad burguesa, Buenos Aires, Amorrortu, 1971.

76. Kotlikoff, L. J. "What microeconomics teaches us about the dynamic macro effects of fiscal policy", Journal of Money, Credit and Banking 20, 3, 1988, pp. 479-495.

77. Krugman, P. "A model of innovation, technology transfer, and the world distribution of income”, Journal of Political Economy 87, 2, 1979, pp. 253-266.

78. Kuznets S. Modern economic growth, rate structure and spread, New Haven, Yale University Press, 1966.

79. Lewis, S. R. Jr. "Government Revenue from Foreign Trade: An International Comparison", The Manchester School of Economic and Social Sciences 31, 1963, pp. 36-45.

80. Lewis, W. A. Teoría del desarrollo económico, México, Fondo de Cultura Económica, 1955. 
81. Lewis, W. A. Teoría de la planificación económica, México, Fondo de Cultura Económica, 1966.

82. Lotz, J. R. y E. R. Morss. “Measuring 'tax effort' in developing countries”, IMF Staff Papers 14, 3, 1967, pp. 478-497.

83. Mankiw, N. G. "Recent developments in macroeconomics: A very quick refresher course", Journal of Money, Credit and Banking 20, 3, 1988, pp. 436-449.

84. Mankiw, N. G. y D. Romer. New Keynesian economics, vols. I y II, Cambridge, MIT Press, 1991,

85. Mankiw, N. G., M. Weinzierl y D. Yagan. "Optimal taxation in theory and practice", Journal of Economic Perspectives 23, 4, 2009, pp. 147-174.

86. Mann, M. Las fuentes del poder social I, Madrid, Alianza, 1986.

87. Mann, M. Las fuentes del poder social II, Madrid, Alianza, 1997.

88. Martin, A. y W. A. Lewis. "Pattern of public revenue and expenditure", Manchester School of Economic and Social Studies 24, 1956, pp. 203-244.

89. McCallum, B. T. "Postwar developments in business cycle theory: A moderately classical perspective", Journal of Money, Credit and Banking 20, 3, 1988, pp. 459-471.

90. McKinnon, R. I. Dinero y capital en el desarrollo económico, México, CEMLA, 1974.

91. Meir, G. y J. E. Stiglitz, eds. Fronteras de la economía del desarrollo: el futuro en perspectiva, Bogotá, Banco Mundial y Alfaomega, 2001.

92. Miller, P. J. The rational expectations revolution, Cambridge, MIT Press, 1994.

93. Mirrlees, J. A. "An exploration in the theory of optimal income taxation", Review of Economic Studies 38, 2, 1971, pp. 175-208.

94. Mirrless, J. et al. Dimensions of tax design, Oxford, Oxford University Press - Institute for Fiscal Studies, 2010.

95. Mitra, P. y N. Stern. “Tax systems in transition”, World Bank Policy Research Working Paper 2947, 2003.

96. Mkandawire, T. "On tax efforts and colonial heritabe in Africa", Institutet för Framtidsstudier Working Paper 2010-10, 2010.

97. Morag, A. Impuestos e inflación, Barcelona, Vicens-Vives, 1973.

98. Morison, S. E., H. S. Commager y W. E. Leuchtenburg. Breve historia de los Estados Unidos, México, Fondo de Cultura Económica, 1999.

99. Musgrave, R. A. Sistemas fiscales, Madrid, Aguilar, 1969.

100. Newbery, D. y N. Stern. The theory of taxation for developing countries, Washington, The World Bank y Oxford University Press, 1987.

101. Norregaard, J. y T. S. Khan. "Tax policy: Recent trends and coming challenges", IMF Working Paper 07/274, 2007.

102. Nurkse, R. Problemas de formación de capital en los paises insuficientemente desarrollados, México, Fondo de Cultura Económica, 1953.

103. Ocampo, J. A., ed. El desarrollo económico en los albores del siglo XXI, Bogotá, CEPAL y Alfaomega, 2004.

104. Olivera, J. H. "Money, prices and fiscal lags: A note on the dynamics of inflation", Banca Nazionale del Lavoro Quarterly Review 20, 1967, pp. 258-267.

105. Piggott, J. y J. Whalley. "VAT base broadening, self supply, and the informal sector”, American Economic Review 91, 2001, pp. 1084-1094. 
106. Portales, C., comp. La América Latina en el nuevo orden económico internacional, México, Fondo de Cultura Económica, 1983.

107. Prebisch, R. "El desarrollo económico de la América Latina y algunos de sus principales problemas", Boletín Económico de América Latina 7, $1,1949$.

108. Prebisch, R. "Prólogo", O. Rodríguez, ed., La teoría del subdesarrollo de la CEPAL, México, Siglo XXI, 1980.

109. Reisen, H. "Interaction between the exchange rate and the public budget in major debtor developing countries", V. Tanzi, ed., Fiscal policy in open developing economies, Washington, IMF, 1990.

110. Rodríguez, O. La teoría del subdesarrollo de la CEPAL, México, Siglo XXI, 1980.

111. Romanov, D. "Costs and benefits of marginal reallocation of tax agency resources in pursuit of the hard-to-tax", AYSPS Conference: The hard-to-tax. An international perspective, Atlanta, Georgia State University, 2003.

112. Ros, J. La teoría del desarrollo y la economía del crecimiento, México, Fondo de Cultura Económica, 2004.

113. Rostow, W. W. Las etapas del crecimiento económico. Un manifiesto no comunista, México, Fondo de Cultura Económica, 1960.

114. Seade, J. "Tax revenue implications of exchange rate adjustment", V. Tanzi, ed., Fiscal policy in open developing economies, Washington, IMF, 1990.

115. Sen, A. Desarrollo y libertad, Planeta, Bogotá, 1999.

116. Singer, H. W. "La mecánica del desarrollo económico", 1952, A. N. Agarwala y S. P. Singh, eds., La economía del subdesarrollo, Madrid, Tecnos, 1973.

117. Smith, A. Investigación sobre la naturaleza y causas de la riqueza de las naciones, 1776, México, Fondo de Cultura Económica, 1987.

118. Snowdon, B. y H. R. Vane, eds. A macroeconomics reader, London, Routledge Press, 1997.

119. Stiglitz, J. E. Whither socialism?, Cambridge, MIT Press, 1994.

120. Stotsky, J. G. y A. WoldeMariam. "Tax effort in Sub Saharan Africa", IMF Working Paper 97/107, 1997.

121. Sunkel, O. y P. Paz. El subdesarrollo latinoamericano y la teoría del desarrollo, México, Siglo XXI e ILPES, 1982.

122. Talvi, E. y C. A. Végh. "Tax base variability and pro-cyclical fiscal policy”, NBER Working Paper Series 7499, 2000.

123. Tanzi, V. "Inflation, real tax revenue and the case of inflationary finance", IMF Staff Papers 25, 1978, pp. 417-451.

124. Tanzi, V. Taxation, inflation, and interest rates, Washington, IMF, 1984.

125. Tanzi, V. "Fiscal policy responses to exogenous shocks in developing countries", American Economic Review 76, 2, 1986, pp. 88-91.

126. Tanzi, V. "Quantitative characteristics of the tax systems of developing countries", D. Newbery y N. Stern, eds., The theory of taxation for developing countries, Washington, The World Bank y Oxford University Press, 1987. 
127. Tanzi, V. “The impact of macroeconomic policies on the level of taxation (and on the fiscal balance) in developing countries", IMF Working Paper 88/95, 1988.

128. Tanzi, V. "Fiscal policy and economic reconstruction in Latin America", IMF Working Paper 89/94, 1989.

129. Tanzi, V. Fiscal policy in open developing economies, Washington, IMF, 1990.

130. Tanzi, V. "Globalization and the need for fiscal reform in developing countries", Journal of Policy Modeling 26, 2004, pp. 525-542.

131. Tanzi, V. y H. Zee. La politica tributaria en los paises en desarrollo, Washington, FMI, 2001.

132. Thorp, R. y L. Whitehead, eds. La crisis de la deuda en América Latina, Bogotá, Siglo XXI y Fedesarrollo, 1986.

133. Thuronyi, V. "Presumptive taxation of the hard tax", mimeo, 2003.

134. UNESCO. Historia de la humanidad, vol. 9, Barcelona, Planeta, 1963.

135. Wallace, S. "Imputed and presumptive taxes: International experiences and lessons for Russia”, AYSPS Working Papers 02-03, 2002. 